University of Nebraska - Lincoln

DigitalCommons@University of Nebraska - Lincoln

PreColumbian Textile Conference VIII /

Jornadas de Textiles PreColombinos VIII (2019)

Centre for Textile Research

$6-2020$

\title{
Un fundamento de la textualidad textil: los colores Tarabuco
}

Ricardo Cavalcanti-Schiel

Universidad Federal de Río Grande del Sur (UFRGS), Porto Alegre, Brasil, riccaval@yahoo.com.br

Follow this and additional works at: https://digitalcommons.unl.edu/pctviii

Part of the Art and Materials Conservation Commons, Fiber, Textile, and Weaving Arts Commons, Indigenous Studies Commons, Latin American Languages and Societies Commons, Museum Studies Commons, and the Other History of Art, Architecture, and Archaeology Commons

Cavalcanti-Schiel, Ricardo, "Un fundamento de la textualidad textil: los colores Tarabuco" (2020). PreColumbian Textile Conference VIII / Jornadas de Textiles PreColombinos VIII (2019). 23.

https://digitalcommons.unl.edu/pctviii/23

This Article is brought to you for free and open access by the Centre for Textile Research at DigitalCommons@University of Nebraska - Lincoln. It has been accepted for inclusion in PreColumbian Textile Conference VIII / Jornadas de Textiles PreColombinos VIII (2019) by an authorized administrator of DigitalCommons@University of Nebraska - Lincoln. 


\title{
21
}

\section{Un fundamento de la textualidad textil: los colores Tarabuco}

\author{
Ricardo Cavalcanti-Schiel \\ Departamento de Antropología, Universidad Federal de Río Grande del Sur (UFRGS), Porto Alegre, Brasil.
}

\section{Resumen}

El presente artículo tiene por objetivo presentar la lógica de funcionamiento de una gramática del color en los textiles tarabuco de los Andes Meridionales (centro-sur de Bolivia). Poniendo foco en el sistema de k'uychi, un dispositivo prescriptivo de gradación cromática (degradé), se pretende demostrar como él funciona como mecanismo de construcción de un lenguaje expresivo, coherente con los fundamentos cosmológicos andinos.

Palabras claves: Andes, Tarabuco, textiles, semiótica, colores.

\begin{abstract}
The purpose of this article is to present the logic of operation of a color grammar in Tarabuco textiles of the Southern Andes (south-central Bolivia). Focusing on the system of k'uychi, a prescriptive device of chromatic gradation (dégradé), it is intended to demonstrate how it works as a mechanism for building an expressive language, consistent with the Andean cosmological foundations.
\end{abstract}

Keywords: Andes, Tarabuco, textiles, semiotics, colours.

\section{Résumé}

Le but de cet article est de présenter la logique de fonctionnement d'une grammaire des couleurs dans les textiles tarabuco du sud des Andes (centre-sud de la Bolivie). En se concentrant sur le système de k'uychi, un dispositif normatif de gradation chromatique (dégradé), il essaie de démontrer son fonctionnement en tant que mécanisme de construction d'un langage expressif, cohérent avec les fondements cosmologiques andins.

Mots clés: Andes, Tarabuco, textiles, sémiotique, couleurs.

"El mundo es lo que vemos y, sin embargo, tenemos que aprender a verlo."

Maurice Merleau-Ponty (Lo visible y lo invisible. Barcelona: Seix Barral, 1966, p. 20).

\section{Los Tarabuco y el objeto del presente análisis}

Lo que se puede llamar los Tarabuco es un conjunto de alrededor de siete decenas de comunidades indígena-campesinas de habla quechua, ubicadas en el entorno del pueblo que lleva este nombre, situado a $55 \mathrm{Km}$ a estesudeste de la ciudad de Sucre, capital del Departamento de Chuquisaca, en el centro-sur de Bolivia. La región en la que se encuentran estas comunidades se constituye como la más oriental de las estribaciones de la Cordillera de los Andes, en terrenos accidentados entre los 3.100 y los 3.400 m.s.n.m. Acerca de esta precisa serranía, que recibe el nombre de Cordillera de Mandinga (cuyas cumbres alcanzan los 3.750 m.s.n.m.), el naturalista y explorador francés Alcide d'Orbigny observó en 1832 tratarse de "la cresta divisoria de las aguas de la

DOI: $10.32873 /$ unl.dc.zea.1221

Published in PreColumbian Textile Conference VIII / Jornadas de Textiles PreColombinos VIII, ed. Lena Bjerregaard and Ann Peters

(Lincoln, NE: Zea Books, 2020). https://digitalcommons.unl.edu/zeabook/ 
cuenca del Plata y la del Amazonas" (d'Orbigny 1844:274. Traducción mía). En otra perspectiva, esta gente a la que llamamos Tarabuco está ubicada en el tercio norte del arco quechua que voltea por oriente, hacia el sur, el Altiplano aymara, y se ha conformado, a lo largo de varios siglos (uno de ellos, al menos, antes de la llegada de los europeos), como una fusión de gente local - que algunos creen ser los Yampara (minoritarios ${ }^{1}$ ), sin que se sepa exactamente qué significaba esta referencia - con contingentes venidos de varias partes de los Andes, en especial con la implantación de colonias estatales (mitmaqkuna) en el incario en todo este arco quechua. De no ser así, no habría otra razón para la masiva persistencia de la lengua quechua.

A lo largo del período histórico, este "amasijo étnico"- si se puede decirlo así, de modo muy precario y equivocadamente pasivo- se fue consolidando, bajo el lenguaje reciprocitario y en el marco del proceso de provincianización de los indios (Cavalcanti-Schiel 2008), como una gobernación dual (pero, al parecer, no dualista - acorde el referente antropológico clásico), que conformó códigos y discursos propios y distintivos. El textil es el soporte de uno de ellos. El otro es su calendario ritual. De este modo, aunque el uso de los textiles tradicionales se pueda ir perdiendo en varias partes, incluso en comunidades enteras, la gente Tarabuco comprende su lenguaje. Es acerca de una parte de la semiótica de este lenguaje, la que se refiere al color, que este texto tratará.

Los Tarabuco son muy visibles en el escenario turístico boliviano. La feria dominical en el pueblo cuyo nombre le sirve de referencia - comúnmente se los dicen tarabuqueños- , además del evento músico-coreográfico del Pukllay que ocurre cada año una semana después del carnaval, con su masiva presencia indígena, son atractivos que llenan el lugar de turistas, a semejanza (aunque en menor escala) de Chivay, en el Valle del Colca, del departamento peruano de Arequipa. Si el "carnaval de Tarabuco" ha sido tomado prestado del calendario ritual, los ponchos rojizos a bandas horizontales (los únicos usados con esta disposición en los Andes) - acompañados de las monteras masculinas que se semejan a morriones españoles- y la vistosa iconografía de algunas de las prendas vestimentarias, son los elementos del otro código expresivo que atraen la atención de la gente de afuera y se disponían, hasta hace unas décadas, como la expresión visual paradigmática de una Bolivia "profunda”.

Curiosamente, son hasta ahora bastante escasos los documentos iconográficos de más de 70 u 80 años que permitan acceder a un reconocimiento preciso de los patrones textiles más antiguos de esta gente. Esto incluye a los propios textiles preservados, ya que eran enterrados con sus dueños o entonces, una vez muertos sus dueños, se transformaban, también ellos, en piezas "muertas", sin uso vestimentario, empleados para cargar leña o carbón, en lo que se iban paulatinamente destrozando. La comercialización de estas piezas para la gente de afuera no ha sido siempre un hecho trivial como es hoy. En la mitad de la década de 10 del siglo $\mathrm{XX}$, en una visita a la región, el antropobiólogo belga Georges Rouma, que vivió varios años en Sucre, registra, junto con media docena de imágenes posteriormente publicadas, que los indígenas se negaban de forma vehemente a vender sus tejidos (Rouma 1933:27).

En 1911, el explorador y economista francés Paul Walle hace un registro de un par de indios cargadores de Sucre para su obra La Bolivie et ses mines - publicada tres años después- en que se trata casi seguramente de gente Tarabuco (Walle 1914:facing page 132). En 1903-1904 Julien Guillaume registra imágenes - similares a las que Rouma haría diez años después- para la misión de la Sociedad de Antropología de París, publicadas por Arthur Chervin (1908:42-43, fig. 27-28). Antes de estas imágenes de los albores del siglo XX, sólo disponemos de un muy ambiguo grabado de tipos nativos, bosquejado por Alcide d'Orbigny hacia 1832 y terminado por Jules Boilly para la obra Voyage dans l'Amérique Méridionale (D’Orbigny 1847: lámina “Costumes $\mathrm{n}^{\mathrm{0}} 13$ ”). El grabado está titulado "Indios y mestizos de la nación quechua, de Chuquisaca y su entorno", y muestra, entre cuatro tipos, una pareja portando sombreros como los de la Figura 1 (abajo) y tejidos a rayas de color que sugieren vagamente que pudieran ser gente Tarabuco.

Ya casi a mitad del siglo XX, entre 1939 y 1946, es decir, poco antes de la Revolución Nacionalista del 52 y de la Reforma Agraria que le siguió, el fotógrafo y etnólogo francés Pierre Verger registró 119 imágenes en Tarabuco. Estas, custodiadas por la Fundación Pierre Verger en Salvador (Bahia, Brasil), son probablemente las primeras en las que se puede apreciar con precisión los detalles textiles (salvo por la ausencia capital de color), además de, en cierta medida, consagraren lo que, en los registros precedentes, estaba todavía dubio y variable: el uso del poncho masculino con las bandas cromáticas en la posición horizontal.

La técnica textil y la iconografía tarabuco han sido exploradas de forma precursora por Lynn Meisch en los años 80 del pasado siglo (Meysch 1985a, 1985b, 1986, 1987). Enseguida, el sentido del diseño textil ha sido sistemáticamente explorado por los investigadores de la Fundación Antropólogos del Surandino (ASUR), que mantiene un museo textil

1. Para el caso del "Repartimiento de Indios de Tarabuco y Presto", por ocasión de la Visita General del Virrey Francisco de Toledo en 1573, el contingente advenedizo llegaría a un 92\% de la población (Archivo General de la Nación, Buenos Aires [AGN], División Colonia, Sección Gobierno IX-17.2.5, "Libro de Retazas Libradas por el Ex. ${ }^{\circ}$ S. Toledo, 1785", f. 197v). 


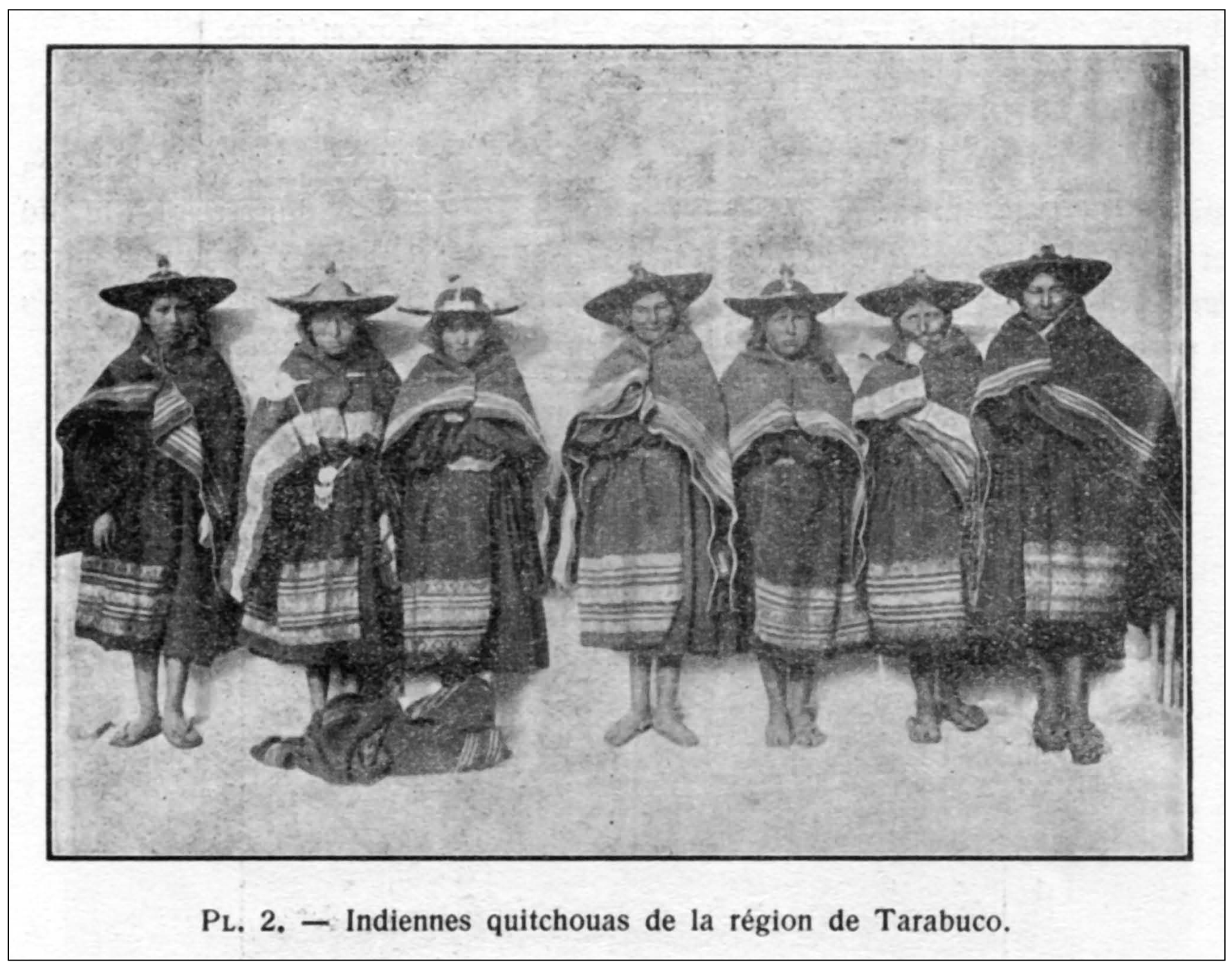

Figura 1. Foto realizada por Georges Rouma entre 1913 y 1916 entre los comuneros de Cororo y Vila-Vila, región de Tarabuco (Rouma 1933:22).

en Sucre y un programa de valoración y apoyo a la tradición textil indígena en el norte de Chuquisaca (Dávalos, Cereceda \& Martínez 1992; Cereceda 1993; Cereceda, Pórcel, Quispe \& Coronado 2013). Todos estos trabajos han explorado el sentido general de la relación entre técnica e iconografía, pero no llegaron a detenerse en la semiótica constitutiva del mensaje textil y su lenguaje de color - salvo en el ejercicio comparativo, hecho por los investigadores de ASUR, con los textiles Jalq'a de la región norte del departamento (cuyos circuitos de comunicación mutua en tiempos pasados todavía se desconoce).

De otra parte, el tema del color (y no de los colorantes) en los textiles históricos y etnográficos andinos (y no en los arqueológicos) ha sido objeto de relativamente pocos trabajos (Femenias 1987; Cereceda, 1987, 1990; Dransart 2002,
2016, 2018; Phipps 2003; Havenon 2004; Fernández López 2008; Espejo 2010; Arnold \& Espejo 2012). El caso Tarabuco nos parece precisamente aquél en el que este tema asume una dimensión de lenguaje particularmente relevante, en donde, como propondré aquí, un cierto código organizativo parece estar a medio camino entre un sistema clasificatorio y un sistema de tipo fonético - sin avanzar hacia el debate sobre si esta condición acerca o no ese código al polémico concepto de semi-simbólico (Greimas 1984:20-22; Floch \& Thürlemann 1986)- , para conformar una semiótica de la memoria social anclada en una cierta percepción ordenada del espacio. En este sentido, la presente nota sigue las huellas de los análisis fundacionales de Verónica Cereceda $(1978,1987,1990)$ sobre la semiótica de los textiles andinos, pero le da otro énfasis analítico, hacia más allá del 


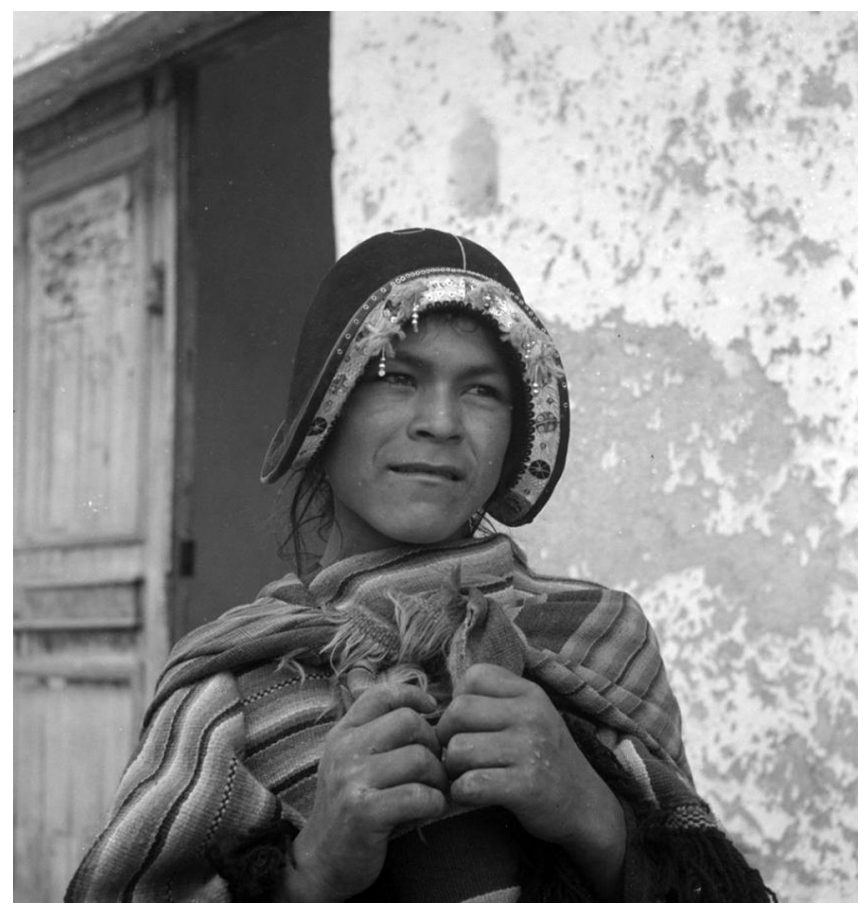

Figura 2: Muchacho Tarabuco. Foto de Pierre Verger (1939-46), cedida por la Fundación Pierre Verger.

paradigma de los grandes contrastes (el paradigma del allqa - Cereceda 1990) como principio e ideal virtuoso del reconocimiento de la imagen y de lo "plástico" en el mundo de los humanos (andinos), volviendo un poco más de atención hacia lo que Lévi-Strauss (1964) designó como la dialéctica entre los pequeños y los grandes intervalos, asimismo que hacia la virtud del discernimiento que se inscribe en la discontinuidad sutil.

\section{El lenguaje textil}

En el mercado de arte étnico, los tejidos tarabuco son conocidos, antes que todo, por su riquísima figuración. La parte figurativa de los textiles tarabuco - aunque pueda ser predominantemente geométrica- recibe la designación quechua pallay. El término se refiere tanto a "diseño" (en la forma nominal) cuanto (en la forma verbal) a "recoger", "cosechar los frutos". En la terminología textil, el pallay contrasta con la pampa, la porción monocromática, donde no se inscribe la diferenciación visual. Pampa es el vocablo que a su vez expresa también la concepción "agrícola" de campo llano, abierto, limpio, en el que la Pachamama puede dispensar fertilidad, ya sea para los cultivos o bien para los rebaños. Desde su acepción cosmológica, Verónica Cereceda concluye: "Pampa, pues, se refiere a un /continuo uniforme/ que nos recuerda la percepción disminuida [por oposición a 'aguda'] de la época sin sol” (Cereceda 1990:93).
Estos dos elementos complementarios (pampa y pallay) componen la pieza femenina por excelencia de la vestimenta tarabuco, una sobrefalda llamada aqsu (véase la Figura 1). De otra parte, en la pequeña bolsa masculina destinada a cargar hojas de coca sólo hay pallay. En la manta que las mujeres portan alrededor del torso, la lliklla, predomina la pampa, complementada por franjas de color (véase también la Figura 1). En ninguna pieza masculina se inscribe la complementariedad pallay-pampa. Se puede decir que el pallay juega un rol decisivo en el horizonte complementario cuando tiene que ver con el cuerpo femenino. Para el cuerpo masculino, este juego se da de otro modo.

El presente texto no tratará específicamente de la figuración tarabuco, el ámbito del pallay, donde potencialmente la tejedora puede inscribir cualquier imagen visible del mundo (o cualquier imagen del mundo visible y discernible, que es este mundo, el kay pacha, que la narrativa cosmológica andina asigna a la era/espacio que se sigue al surgimiento del sol), incluso imágenes estilizadas y geométricas, bajo un sentido de orden multitudinario y abundante. Aunque parezca menos interesante, este texto tratará de otro par complementario de la semiótica textil tarabuco: el que se establece entre franjas de color ordenadas y la misma pampa monocromática. Es este el par que constituye la pieza masculina por excelencia, el poncho.

Si la gramática textual de la composición del pallay supone orden, secuenciación y repetición de los motivos iconográficos, como las hileras de trigo, cebada, papa, maíz, habas, arveja y quinua sembradas en el suelo fértil de la pampa, también las franjas de color de los ponchos (y unkus - otra pieza masculina, una suerte de poncho en miniatura que se lleva sobre los hombros y sobre las nalgas) son ordenadas de un modo específico. El elemento o, más bien, el régimen de ordenamiento de las franjas de color es el k'uychi. Esta voz quechua se reporta precisamente al arcoíris. Pero el arcoíris es más que un fenómeno meteorológico; es más que una metáfora o un ícono sustantivo. Como en muchos otros casos de la cosmología andina, estamos frente a un sujeto de potencia, como los apus (los cerros protectores) y los remolinos de viento (los vientos malos, saqra wayra, que pueden enfermar y robar el alma).

El k'uychi, en el mundo Tarabuco, es a un tiempo forma, manifestación y potencia genésica; es una fuerza vital, que también es potencialmente descontrolada. Se dice que el arcoíris nasce en una fuente de agua y muere en otra, es decir, transita entre dos espacios liminales, entre el mundo iluminado y bien perceptible de la superficie y el mundo oscurecido y difuso (o, más bien, difusamente oscurecido, indiscernible) del "más adentro", el pasado primordial. Si alguien se encuentra con un arcoíris, este puede entrarle por la boca, hacerle caer los dientes y resecarle el 


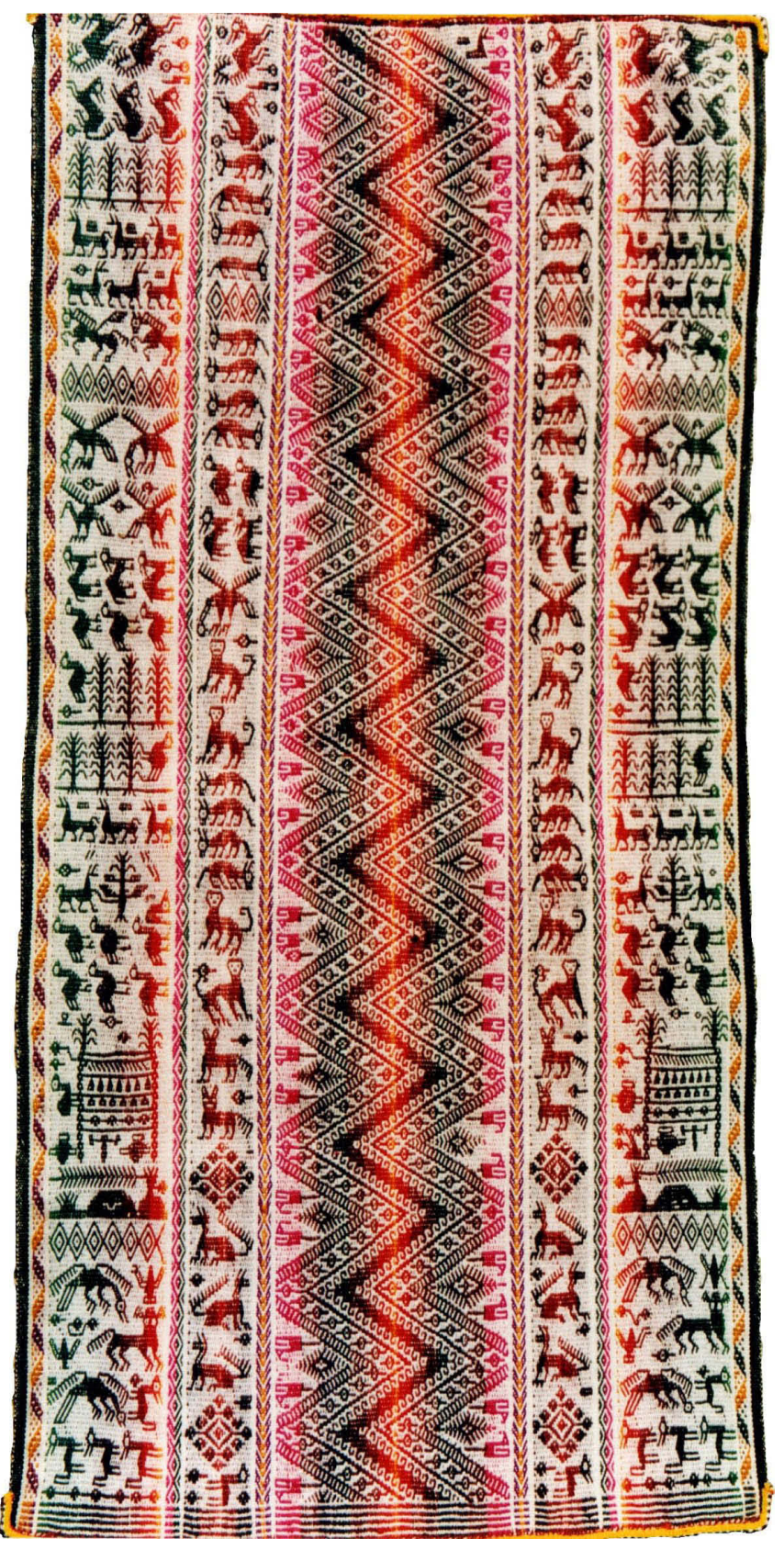

Figura 3. Pallay tarabuco como ejemplo de figuración. Esta clase de pieza no tiene valor vestimentario una vez que no tiene pampa; es tejida tan sólo para vender a los turistas como ícono de "arte étnico". Foto del autor.

estómago, llevando la persona a la muerte. Por eso se dice que cuando está un arcoíris en el cielo uno no puede reírse, es decir, enseñarse los dientes brillantes, o entonces corretear de una parte a otra, atrayendo al arcoíris, por una suerte de simpatía cromática, con los colores de sus ropas, dando margen a que sea perseguido por él. Todo esto conforma el arcoíris como una potencia característica de los sujetos de una otra naturaleza, la del mundo otro paradigmático, el mundo de adentro, el ukhu pacha, donde se encuentran también las demás fuerzas genésicas primordiales, como la Pachamama, es decir, las que comparten la condición de wak’a.

Acercarse a esta potencia por medio del trabajo textil resulta ser entonces una forma de entablar un negocio con ella (un negocio que parte de lo sensible y va hacia lo inteligible), "domesticarla" (en el sentido de traerla hacia el ámbito "de acá"), hacerla fértil y productiva, inscribirla en una cartografía vestimentaria de este mundo (kay pacha). Toda la tejeduría tarabuco - aunque casualmente produzca una pieza que se destine a los hombres- parece estar ensamblada en los términos de un laborioso ejercicio femenino de la fertilidad; una fertilidad que se la recibe de las wak'a, de las potencias de un pasado que entrega al presente su posibilidad de continuidad. El k'uychi, mientras esfuerzo "domesticador" (por medio del discernimiento), resulta ser, como el encadenamiento de los motivos iconográficos del pallay, una gramática del ordenamiento de la luminosidad; ordenamiento que, de su parte, puede ser reconocido como el negocio visual por antonomasia entre las potencias de los dos mundos complementarios.

Grosso modo, el k'uychi es una secuencia preestablecida de tonos, utilizada como una suerte de leimotiv visual. A diferencia de las k'isas aymaras, objeto del análisis de Cereceda (1987:184-216), los k'uychis textiles tarabuco no son, en regla, ni estrechos ni económicos en cantidad, ni tienen función de enlace. Abundan a punto de conformarse como elemento principal de la construcción de la imagen textil de los ponchos y unkus que, de igual modo a la figuración de los pallays, están constituidos precisamente por esta abundancia, ya ahora, en color. Sin embargo, hay seis, y sólo seis, de estas secuencias de tonos, que van agrupadas en tres conjuntos, conforme la destinación socio-ritual de los tejidos que conforman.

Los tres grupos de k'uychis son el de: (1) los de uso diario (genéricamente dicho "grupo rojo", en quechua, puka); (2) los de uso en trajes de luto; y (3) el indiferente (se puede utilizar tanto en tejidos para vestimentas corrientes cuanto en aquellas de luto). El k'uychi es materializado, en lo que respeta a la cadena operatoria de producción textil, por la disposición de hilos de urdimbre, que van a conformar la cara visible del tejido (mientras la trama queda escondida adentro de la estructura textil, como es tradicional en el patrón textil de cara de urdimbre). Las secuencias de tonalidades de los hilos que componen los k'uychis son las que se siguen: 


\begin{tabular}{|c|c|c|}
\hline “ARCOÍRIS” & DESIGNACIONES NATIVAS MÁS USUALES DE LOS TONOS & TRADUCCIÓN APROXIMADA \\
\hline \multicolumn{3}{|c|}{ 1. Grupo puka ("rojo"), uso a diario } \\
\hline $\begin{array}{l}\text { q'illu k’uychi } \\
\text { (“amarillo”) }\end{array}$ & $\begin{array}{c}\text { guindo (o q'illu maman) } \\
\text { yana prusela (o puka prusela) } \\
\text { puka } \\
\text { prusela } \\
\text { aruma } \\
\text { muruchi } \\
\text { q'illu }\end{array}$ & $\begin{array}{c}\text { carmesí oscuro } \\
\text { carmesí o guindo } \\
\text { rojo } \\
\text { leonado } \\
\text { anaranjado } \\
\text { amarillo oro } \\
\text { amarillo azufre }\end{array}$ \\
\hline $\begin{array}{l}\text { rosado k’uychi } \\
\text { ("rosado") }\end{array}$ & $\begin{array}{l}\text { yana guindo (o rosado maman) } \\
\text { puka guindo } \\
\text { rosado qhipan (o puka rosado) } \\
\text { rosado }\end{array}$ & $\begin{array}{l}\text { púrpura oscuro } \\
\text { rosado-purpúreo } \\
\text { magenta } \\
\text { rosado vivo }\end{array}$ \\
\hline $\begin{array}{c}\text { panti k'uychi } \\
\text { ("vino”) }\end{array}$ & $\begin{array}{c}\text { yana morado (o panti maman) } \\
\text { yana panti } \\
\text { panti } \\
\text { yakupanti }\end{array}$ & $\begin{array}{l}\text { tannat } \\
\text { cabernet } \\
\text { gamay } \\
\text { rosé zinfandel }\end{array}$ \\
\hline \multicolumn{3}{|c|}{ 2. Grupo luto } \\
\hline $\begin{array}{l}\text { morado k'uychi } \\
\text { ("morado") }\end{array}$ & $\begin{array}{c}\text { yana (o morado maman) } \\
\text { yana morado } \\
\text { morado } \\
\text { morado t'ukra }\end{array}$ & $\begin{array}{l}\text { morado oscuro } \\
\text { morado } \\
\text { lila } \\
\text { lila claro }\end{array}$ \\
\hline $\begin{array}{l}\text { celeste k’uychi } \\
\text { (“azul”) }\end{array}$ & $\begin{array}{c}\text { yana (o celeste maman) } \\
\text { yana azul } \\
\text { celeste qhipan (o yana celeste) } \\
\text { celeste (o celestecito) }\end{array}$ & $\begin{array}{l}\text { añil } \\
\text { marino } \\
\text { turquesa } \\
\text { celeste }\end{array}$ \\
\hline \multicolumn{3}{|c|}{ 3. Grupo indiferente } \\
\hline $\begin{array}{l}\text { q'umir k’uychi } \\
\text { ("verde") }\end{array}$ & $\begin{array}{c}\text { yana (o q'umir maman) } \\
\text { yana q'umir } \\
\text { q'umir (o laqhitun q'umir) } \\
\text { q'ichichi }\end{array}$ & $\begin{array}{c}\text { laurel oscuro } \\
\quad \text { laurel } \\
\text { verde bandera } \\
\text { verde manzana }\end{array}$ \\
\hline
\end{tabular}

En la práctica, tenemos algo así:

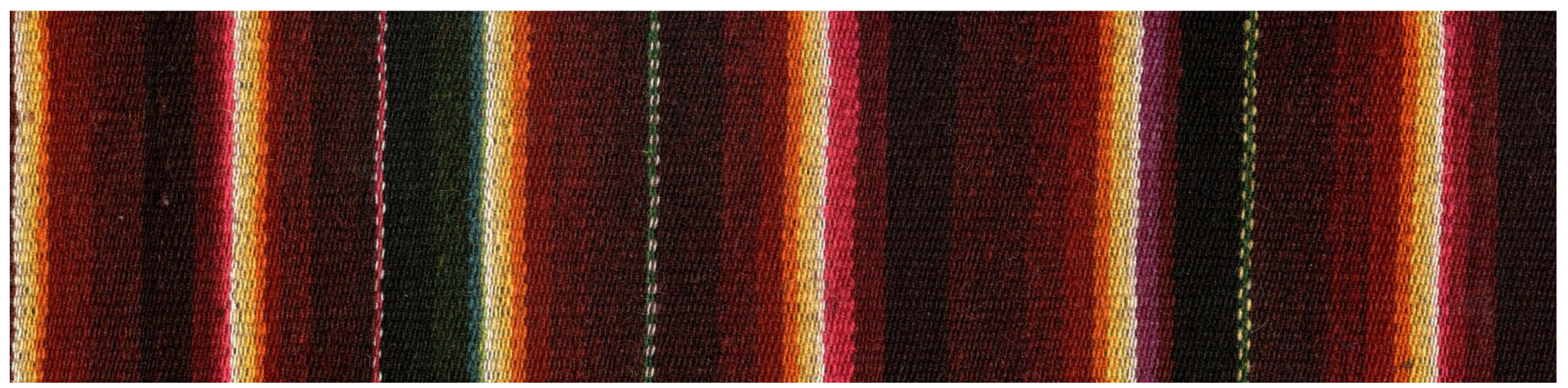

Figura 4. Secuencia de k'uychis del grupo puka en la que se interponen tres q’utus (la mediación de hilos mesclados de larga utilización en los textiles andinos). La secuencia de k'uychis es (de izquierda a derecha; la flecha indica el sentido del tono más oscuro hacia lo más claro): amarillo $(\leftarrow)$, rosado $(\rightarrow)$, amarillo $(\leftarrow)$, q'utu, verde $(\rightarrow)$, amarillo $(\leftarrow)$, q'utu, amarillo $(\rightarrow)$, rosado $(\leftarrow)$, amarillo $(\rightarrow)$, vino $(\leftarrow)$, q'utu, amarillo $\rightarrow$ ), rosado $(\leftarrow)$. Foto del autor. 
Caben algunas observaciones:

1. Estas secuencias y sus conjuntos de tonos son restrictivas: no se puede inventar k'uychis; no se puede intercambiar tonos. Sin embargo, puede que una tejedora no necesariamente aplique todo el espectro de tonos de un $k$ 'uychi en una pieza. Los casos más notables de "falta" de tonos ocurren, en general, en los k'uychis verde y vino. Pero lo más importante es que se mantenga el orden: el "degradé" de tonos.

2. La construcción operatoria del k’uychi dispone siempre más hilos de urdimbre para los tonos más oscuros, considerados los tonos "madre" (maman), bajando la cantidad progresivamente, conforme se va hacia los tonos más claros.

3. En la disposición de los hilos de la urdimbre, los k'uychis se encadenan encontrándose o en sus tonos "madre" (más oscuros) o en sus tonos más claros, de modo a producir la impresión - en los textiles actuales particularmente valorada (pero no tanto en los más antiguos) - de la emergencia de una faja estrecha de luminosidad a partir de un fondo más amplio de oscuridad, como se percibe en la Figura 5 (abajo).

4. Como se puede notar en el cuadro precedente, en algunos k'uychis la designación "negro" (yana) simplemente puede repetirse, ocupando el lugar del maman. El uso corriente de una misma designación de tono (yana, "negro") en varios k'uychis sugiere que ahí la proximidad del negro es tan grande que los tonos maman se acercan a la indiferenciación. Sin embargo (o quizá precisamente por eso), las tejedoras tratan de diferenciarlos. Este cuidado no es gratuito, como se va a notar enseguida. Él se hace en contexto, y en un contexto en el que las gradaciones son deliberadamente sutiles. Lo más importante no es la designación singular de un tono ni un reconocimiento preciso de tonos (en términos teóricamente absolutos de frecuencia de onda luminosa), sino el hecho de que los tonos siempre van "emparentados”, se disponen

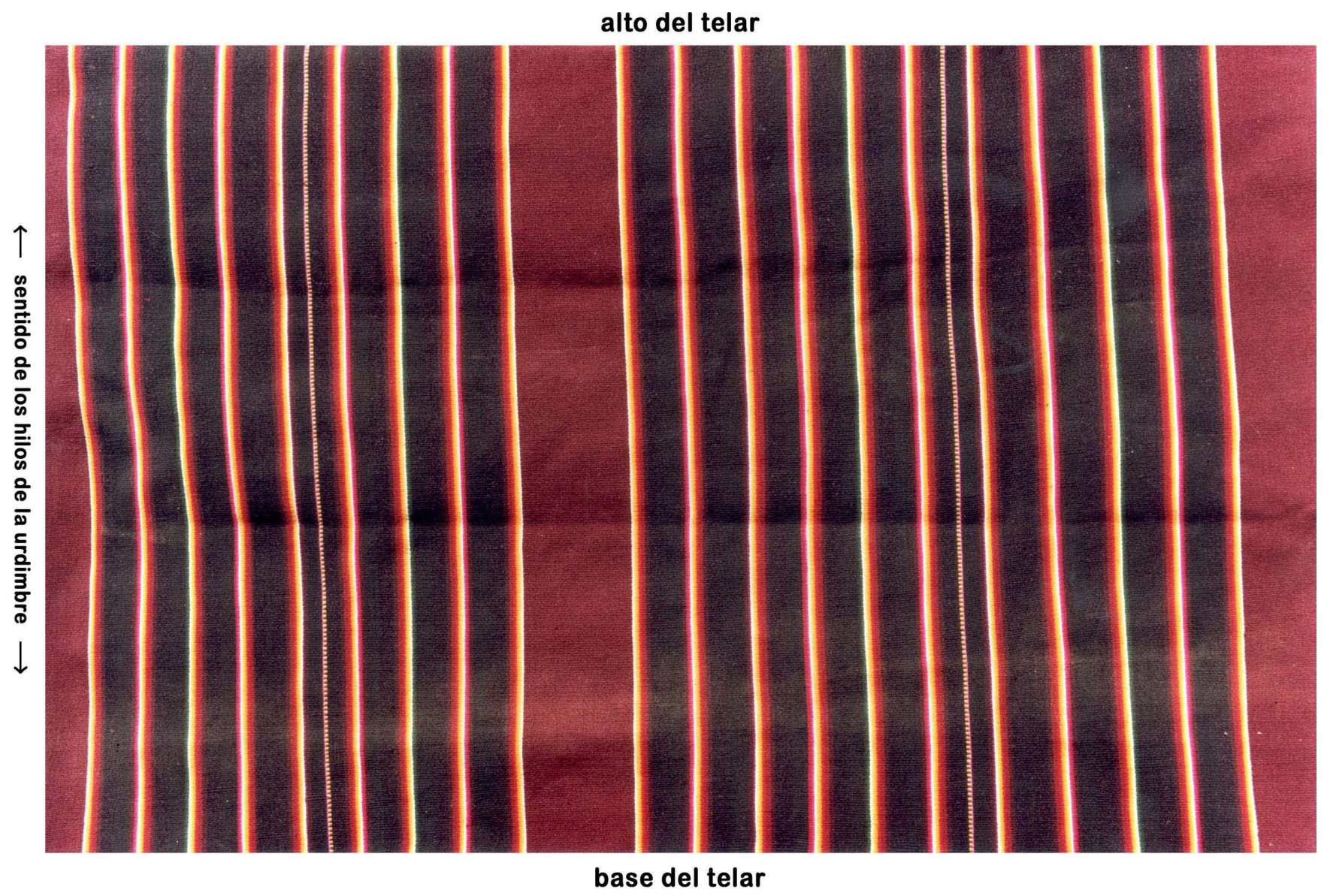

Figura 5. Conjunto completo de k’uychis en una mitad (khallu) recién tejida de un poncho en hilo de lana sintética (más fina). Las fajas oscuras, en las que aquí poco se distingue la gradación de tonalidades son, en realidad, el encuentro de los tonos más oscuros de cada k'uychi. En los extremos y entre estos dos grande conjuntos de k’uychis se interponen fajas de pampa en color guinda, característica de los ponchos de la porción sur de la región de Tarabuco. Foto del autor. 
en relación. Por esta razón, utilicé deliberadamente para el k'uychi "vino" designaciones que se remiten a castas vinícolas europeas, a modo de un código de lenguaje que, como nos sugiere Mary Douglas (1986:91-109), es relativamente arbitrario en lo que toca a las designaciones singulares para los términos, pero donde lo que vale son las relaciones clasificatorias entre los términos.

5. Un cierto tono de negro opaco a veces puede ser usado, con pocos hilos de urdimbre, para insertar un corte entre dos franjas oscuras (maman) de k'uychis iguales dispuestos simétricamente. En este caso, se asegura que los k'uychis mantengan su singularidad de agrupación al mismo tiempo en que se maneja la herramienta de la sutil diferenciación como recurso dispositivo.

6. El blanco (yuraq) actualmente siempre acompaña al k'uychi amarillo y podría ser considerado como parte de este $k$ 'uychi si no sirviera genéricamente como color base sobre el que se inscribe la figuración en la piezas donde ella es realizada (véase la Figura 3). En las piezas actuales, k'uychis y figuración tienden a excluirse mutuamente. Así, se podría decir que donde comparecen k'uychis, el blanco sería el último color del k'uychi amarillo. En algunos casos más raros, en ponchos más antiguos y con flecos de un solo color (que les hace ser llamados fullus - la misma designación que se le da a las frazadas-, y no ponchos), una muy estrecha faja de blanco podía ser usada para separar un k’uychi de otro, lo que nos sugiere que, una vez reconocida la base prescriptiva, siempre se pueden introducir modismos ocasionales. Por evidente, habría que investigarse mejor (si es posible) el contexto de esta clase de piezas antiguas. Estos casos existen, pero son escasos y en ellos los q'utus tienden a ser sustituidos por esta estrecha faja de hilo(s) blanco(s). Así que el blanco parece insinuar, en este caso, la intromisión de una relativa exterioridad, en lugar de la continuidad o la contigüidad.

7. En el grupo puka, el k'uychi amarillo es sobradamente lo más utilizado (véase la Figura 4) y es, por coincidencia, el que tiene más "tonos". Le siguen el rosado, el verde y el vino. En el grupo luto, el k’uychi azul es lo más utilizado, siguiéndole el morado y, más parsimoniosamente, el verde.

Con estas observaciones, creo que se hace claro que el sentido del k'uychi no es otro que el de la necesaria contigüidad de la diferencia sutil, pero una diferencia previamente organizada en términos de relaciones. En esto está el arte del color y del manejo de la modulación perceptiva de la luminosidad, el reconocimiento más fino de la visualidad del kay pacha, que los hombres Tarabuco reconocen como un atributo "cognitivo" esencialmente femenino - así como para ellos, de su parte, les toca mejor el ejercicio de la "música”, que tiene que ver con el ámbito del otro (y complementario) régimen textual de memoria de su gente: el calendario ritual (Cavalcanti-Schiel 2015). Las variaciones cromáticas "sustantivas" adentro de cada k’uychi - sea en el tiempo sea de un subgrupo local de comunidades a otropueden ser considerables. Pero no es esta sustantividad que constituye el fundamento de la discursividad textil tarabuco en términos de color. En base a una gramática prescriptiva, lo que en realidad se ejercita es la sutileza; una sutileza que se ensancha todavía más cuando se "sube" del nivel de k'uychi hacia la composición de agregados de k'uychis, que es lo que, finalmente, constituye el poncho. Es toda esta semiótica que le otorga al color su debido lugar.

Si tomamos el khallu de la Figura 5, podemos observar la forma básica como se compone el juego de asimetrías complementarias de los conjuntos de k'uychis.

En el primer conjunto (el de la izquierda del khallu) tenemos una suerte de centro compuesto: a la derecha de él un q'utu, seguido a su izquierda de un k'uychi vino; a la izquierda de este grupo está un otro k'uychi amarillo. Este centro representa, por si mismo, una complementariedad asimétrica que se replica hacia adentro. No son simplemente dos k'uychis. Una de las “mitades” que compone el centro lleva un q'utu que desestabiliza todo. Sin embargo, si desde este centro compuesto seguimos hacia las extremidades exteriores del conjunto, vamos a encontrar la misma secuencia de $k$ 'uychis con los degradés espejados: amarillo, rosado, amarillo, verde, amarillo, rosado, amarillo. Esto conformaría una simetría - o, en el decir de Catherine Seibold (1992:194), una simetría bilateral frente a un centro destacado- si no fuera por el centro conformarse desde ya como asimétrico, de modo que cualquiera que sea la parte del centro que se considere como componiendo una de las mitades, la otra va a ser siempre distinta de la primera, del mismo modo como el "centro" se constituye, intrínsecamente, de partes desiguales y complementarias.

Si confrontamos este primer conjunto con el segundo (el de la derecha del khallu, que en la Figura 6 está abajo), vamos a encontrar, en primer lugar, que el mismo centro está invertido (o espejado). Desde él, hacia la derecha, vamos a encontrar la misma secuencia de k'uychis del conjunto anterior. En la otra "mitad”, es decir, hacia la izquierda, lo mismo, pero ahora añadido de más cuatro k’uychis (que en la figura van indicados como "sobra"), que son precisamente los cuatro que se desplazan desde la "mitad" del centro hacia la izquierda, en este conjunto, o hacia la derecha, en el otro conjunto, pero, en ambos, sin el q'utu.

Se hace perceptible todo un juego de espejos. Pero en este segundo caso ya no se puede más encontrar simetrías bilaterales. Estamos definitivamente en el ámbito de las 
conjunto de $k^{\prime} u y c h i s$ de la izquierda

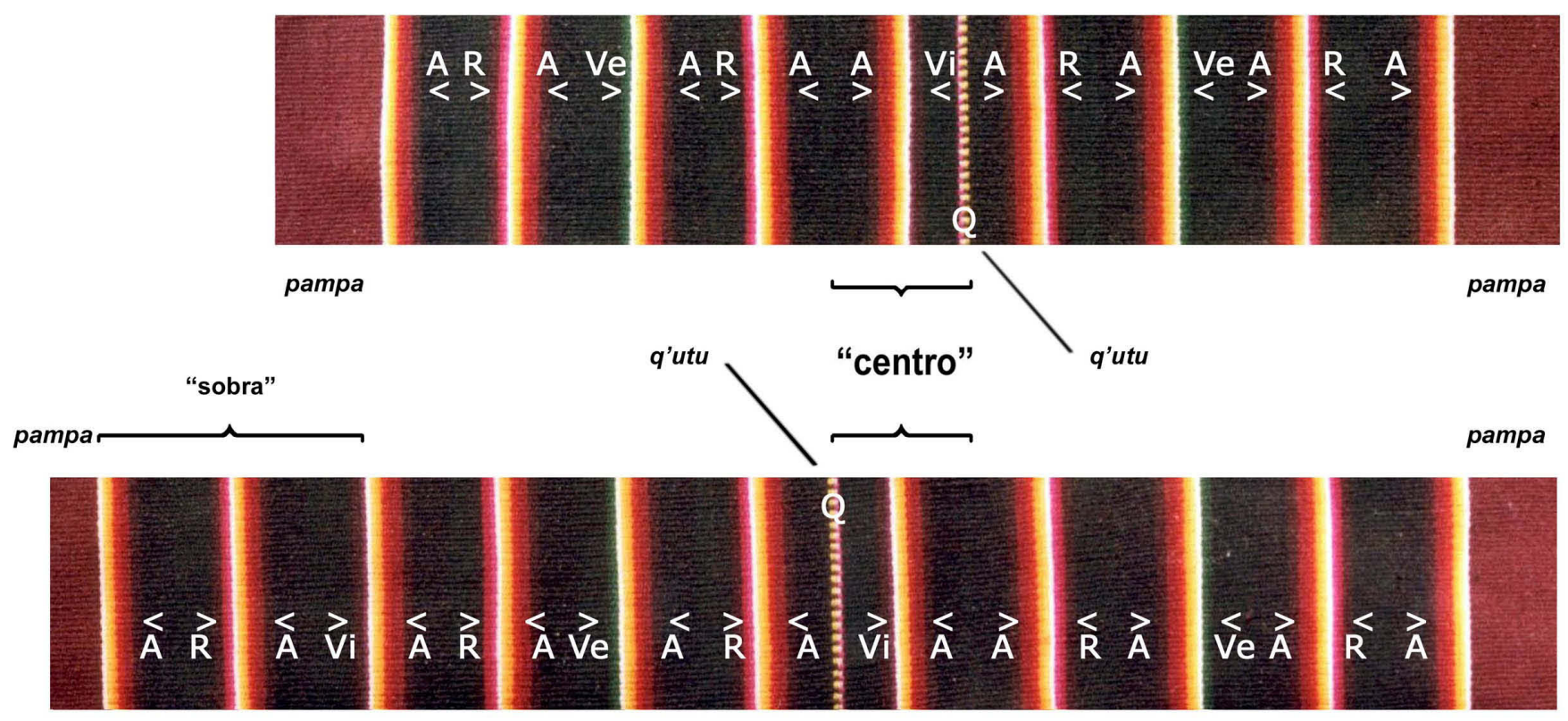

conjunto de $k^{\prime} u y c h i s$ de la derecha

Figura 6. Los conjuntos de k'uychis de una mitad (khallu) de poncho, donde: Q es q'utu; A es k'uychi amarillo; R es rosado; Ve es verde; Vi es vino; $<$ y > indican el orden de los tonos del más oscuro hacia lo más claro. A partir de foto del autor.

asimetrías y reflexiones. Estas últimas no son las especulativas, que atañen al ejercicio de los conceptos, sino que las visuales, las sensibles... y muy sutiles. Ellas hacen con que, al disponerse el segundo conjunto de k'uychis (el que está abajo en la Figura 6) efectivamente a la derecha del primero, como está en realidad en el poncho, lo que encontramos es que sus extremidades hacia afuera, desde los q'utus, se espejan perfectamente. Todo lo que en un momento parece centro, se desplaza enseguida hacia la asimetría, de modo que la sola "solución" es reconocer todo como complementario.

En el mismo sentido, se puede concebir a los conjuntos de k'uychis como complementarios a la pampa (o al revés). De otra parte, no deja de ser interesante notar que si, como regla general de composición, adentro de un pallay (el índice de lo femenino) hay siempre tres franjas figurativas (véase la Figura 3), adentro de un khallu de poncho (el índice de lo masculino) hay siempre tres franjas de pampa monocromática.

El ejemplo ilustrativo que nos permitió el precedente ejercicio no es resultado del trabajo de una tejedora experimentada, en el desempeño de su maestría para la producción de un texto textil particularmente refinado. Bien al revés, se trata de la primera lección de elaboración de un poncho por parte de una muchacha, que la recibió de una mujer más vieja y esta, de su parte, dispuso los hilos de la urdimbre en el telar. En realidad, lo que parece a primera vista razonablemente complejo, para las mujeres tarabuco es tan sólo el punto de partida. Por varias veces, después de intentar "leer" una considerable cantidad de ponchos tarabuco y creerlos regularmente comprensibles, no era raro que me llegara una pieza tejida por alguna viejita y que echara mis pretensiones de comprensión al borde del vértigo.

\section{Hacia una semiótica del cromatismo}

A modo de resumen, se puede decir que, en el contexto textil tarabuco, el k'uychi, como operador de lenguaje, es: (1) organizativo: especifica una relación entre tonos, por medio de cantidades diferidas de hilos de urdimbre para cada uno; (2) prescriptivo: no se pueden crear k'uychis arbitrarios, el conjunto de los k'uychis posibles es fijo y constituye la base por donde se empieza la construcción del textil masculino en que va aplicado (el pocho o el unku), disponiendo una orientación clasificatoria general de la coloración, en la que no se puede utilizar matices de luto en la vestimenta corriente y al revés; y (3) clasificatorio: salvo para el blanco "puro" o el negro "puro", no existe color aislado, todo color sólo existe adentro de un sistema de relaciones. Conclusivamente: en cuanto unidad composicional de la semiótica textil, el k’uychi engendra un sistema lógico. 
De una parte, la lingüística estructural de la Escuela de Praga defendió que la noción de "sistema fonético" se conforma como un conjunto de mutuas relaciones diferenciales entre los sonidos (resultados articulatorios) del habla que instituye posiciones significantes para términos singulares. Si se cambia el término (sonido), cambia el sentido de la enunciación. En este caso, las relaciones especifican términos. En la medida que sirve de base para el reconocimiento de la luminosidad acorde un cierto orden, disponiendo el reconocimiento del matiz en el contexto de una sintaxis complementaria desde elementos mutables, el sistema de k'uychi se acercaría (aunque, en la práctica, de modo un tanto limitado) al principio que rige el sistema fonético, insinuando que, análogamente a los fonemas y morfemas - mientras el motivo del arcoíris mismo no deja de ser un mitema (Lévi-Strauss, 1964, 1968) - , el k’uychi, de su parte, pudiera ser una suerte de "luminema".

De otra parte, Lévi-Strauss (1962) consideraba que la forma más elemental de atribuir un orden de inteligibilidad al mundo es la agrupación de elementos a partir de la intuición sensible. Este orden está entonces determinado por la necesidad intelectual de reconocer, que precede y sólo después especifica la "utilidad" de los elementos. La noción de "sistema clasificatorio" supone que las relaciones especifican grupos en este "ámbito" de lo sensible. Sin embargo, aquí no estamos frente a grupos conformados por cosas distintas, sino que conformados por una misma cosa que se va distinguiendo, de una parte, en parcelas fraccionarias que sólo subsisten por sus reducidas diferencias intervalares (adentro del k'uychi) y, de otra, por su utilidad social de destinación y uso (entre los k'uychis), de modo que si lo sensible es el término del reconocimiento, su organización demanda la instauración de una regla en la que el énfasis recae sobre la relación entre relaciones, más que en la relación entre términos (Lévi-Strauss 1968:13).

Se puede decir, de modo general, que en ambos casos (fonético y clasificatorio), estamos frente a sistemas de producción de sentido operados desde el principio lógico de la discontinuidad y de la precedencia lógica de la relación. Como nos demostraban los trabajos de Verónica Cereceda, la gramática textil andina es un ingenio discursivo coherente con la lógica simbólica de la cosmología. Sin embargo, algo más debe ser añadido e esta proposición general de que no se puede producir discurso sin que sea adentro y acorde a un lenguaje. Y es aquí, en lo que toca a la gramática de este lenguaje, que el sistema de k'uychi nos informa algo acerca de la escala de la discontinuidad, algo que nos permite reforzar el reconocimiento que hizo Cereceda (1987) de una (o la) noción andina de "belleza".

Acorde las proposiciones de Cereceda (1990), el dispositivo más elemental de la semiótica de lo visible en los Andes es la oposición maximizada entre lo claramente distinguible, reconocido como atributo de este mundo solar, y lo difuso y obscuro, atributo del mundo presolar: discreto versus continuo; elaboración humana versus condición prehumana; discernimiento versus imprecisión semántica. Al paradigma del máximo contraste, de la maximización de lo discontinuo hasta alcanzar un dualismo diametral, idealmente simétrico (o lo que Lévi-Strauss (1964) llamó "diatónico"), Cereceda le reconoce la pertinencia de la categoría aymara allqa. El término se reporta, desde los vocabularios de comienzos del siglo XVII, a la distintividad de colores, la oposición tonal, la no miscibilidad, alcanzando el campo semántico de la contrariedad y de la disyunción: "Allqa es la parte sensible de un código que expresa ópticamente 'aquello que no puede estar junto' (...), es decir, lo 'dis-junto'” (Cereceda 1990:67). $\mathrm{Su}$ contrario es suwa, lo indistinto, lo indiscernible y, por extensión, lo "rudo de ingenio".

En el curso de las Mitológicas, Lévi-Strauss nos demuestra que, en el ámbito amerindio, el paso del continuo al discontinuo (análogo a nuestra idea del paso de la naturaleza a la cultura) es estratégico para la fundación del entendimiento humano. Pero de igual modo, son estratégicos sus mediadores. Como mitemas, los venenos (de caza y pesca) y el arcoíris son signos por excelencia de esta mediación. Estos "seres cromáticos" operan

\section{“(...) una dialéctica de los pequeños y grandes inter- valos o, tomando prestados términos convenientes del lenguaje musical, de lo cromático y de lo diató- nico. Todo sucede como si el pensamiento sudame- ricano, decididamente pesimista por su inspiración, diatónico por su orientación, atribuyera al croma- tismo una suerte de maleficencia original, y tal que los largos intervalos, esenciales en la cultura para que exista, y en la naturaleza para que sea pensa- ble por el hombre, sólo puede ser el resultado de la autodestrucción de un continuo primitivo, cuyo po- der se siente todavía hoy en los raros puntos donde ha sobrevivido: ya sea en beneficio de hombre, en la forma de los venenos que ha dominado; ya sea con- tra él, en el arcoíris que no puede controlar". (Lévi- Strauss 1964:285-286. Traducción nuestra).}

Si es cierto que en otras partes el arcoíris no se puede controlar, entre los Tarabuco nuestro sistema de k'uychi resultaría ser su apropiación como pharmakon (veneno/remedio) del discurso textil. En efecto, el cromatismo de sus pequeños intervalos hace mover un juego de emergencia de la luminosidad desde una "profundidad materna", para enseguida generar una profusión fractal (y abundante) de entronques complementarios con los que, al fin y al cabo, se va a reconstituir la complementariedad elemental y generativa 
entre las potencias de los pacha: entre conjuntos de k'uychis y la pampa. Quizá ahí esté, en esta cartografía expresiva del espacio, que a su vez se inscribe sobre la integridad orgánica de los cuerpos, la dialéctica entre los grandes y los pequeños intervalos operada por la mediación de aquél pharmakon.

No se trata entonces tan simplemente de restaurar la disyunción fundadora del allqa, pero de instaurar en su seno una escala en donde el dualismo ya no puede más ser diametral. En el movimiento de los k'uychis, la asimetría puede que no sea otra cosa que sucedánea lógica de la presencia implícita del cromatismo (en el sentido musical lévi-straussiano). En las palabras de Verónica Cereceda, siendo el contrario de la disyunción

(...) la mediación se inscribe entonces al interior de la 'conjunción', pero representa tan sólo una parte de ella; el mundo de la conjunción es el mundo del contacto y la mediación no es todo contacto posible sino tan sólo aquel que, siendo difícil de lograr o siendo peligroso, requiere un intermediario: Es a este contacto 'riesgoso' que se asocia una idea de belleza” (Cereceda 1987:218-219).

La semántica general del discurso textil tarabuco parece apuntar, como insinuamos en algunos momentos, hacia una cartografía expresiva en la que la fertilidad como potencia se despliega en un mensaje acerca de la reproducción de las cosas de este mundo claramente visible y de la existencia misma. La complementariedad generativa, que tiene en el par hombre-mujer (qhari-warmi yanantin: Platt 1978) su referente paradigmático, se traduce aquí en el lenguaje textil en términos de posibilidad de un discernimiento igualmente generativo, al mismo tiempo en que traduce el propio textil como sujeto vivo (Cereceda 1978; Desrossiers, 1982, 1997; Zorn 1987; Arnold 2000), es decir, potencialmente reproductivo y que puede incluso morir. En este sentido, el textil tarabuco parece conformar una cartografía de la potencialidad reproductiva que, al expresar un sentido general de la continuidad en términos de fertilidad y reproducción, no deja de ser una específica cartografía de la memoria social (Cavalcanti-Schiel, 2015).

\section{Bibliografía}

Arnold, Denise.

2000 'Convertirse en persona'. El tejido: la terminología aymara de un cuerpo textil. In Actas de la I Jornada Internacional sobre Textiles Precolombinos, editado por Victòria Solanilla D., pp. 9-28. Department d'Art - Universitat Autònoma de Barcelona, Barcelona.

Arnold, Denise \& Elvira Espejo.

2012 The intrusive $k$ 'isa. Bolivian struggles over color patterns and their social implications. World Art 2(2): 251-278.

Cavalcanti-Schiel, Ricardo.

2008 Por qué los Tarabuco no son descendientes de los Yampara. Anuario de Estudios Bolivianos, Archivísticos y Bibliográficos del Archivo y Biblioteca Nacionales de Bolivia 14: 99-141.

2015 Relativizando la historicidad. Memoria social, cosmología y tiempo en los Andes. Quaderns-e de l'Institut Català d'Antropologia 20(2): 84-104.

Cereceda, Verónica.

1978 Sémiologie des tissus andins: les talegas d'Isluga. Annales ESC 33(5-6): 1017-1035.

1987 Aproximaciones a una estética andina: de la belleza al tinku. In Tres reflexiones sobre el pensamiento andino, Th. Bouysse-Cassagne, Olivia Harris, Tristan Platt \& Verónica Cereceda, pp. 133-226. La Paz: Hisbol.

1990 A partir de los colores de un pájaro... Boletín del Museo Chileno de Arte Precolombino 4: 57-104.

1993 Una diferencia, un sentido: Los diseños de los textiles tarabuco y jalq’a. Fundación Antropólogos del Surandino (ASUR), Sucre.

Cereceda, Verónica, Santiago Pórcel Gira, Román Quispe Flores \& Brígida Coronado A.

2013 Diseños en aqsus Tarabuco-Yampara. Fundación Antropólogos del Surandino, Sucre.

Chervin, Arthur.

1908 Anthropologie bolivienne Tome I. Imprimerie nationale, París.

D’Orbigny, Alcide.

1844 Voyage dans l'Amérique Méridionale Tome Troisième $1^{\text {ère }}$ partie. P. Bertrand/ V Levrault, París/ Estrasburgo.

1847 Voyage dans l'Amérique Méridionale Tome Huitième. P. Bertrand/ Ve Levrault, París/Estrasburgo.

Dávalos, Johnny, Verónica Cereceda \& Gabriel Martínez.

1992 Textiles Tarabuco. Proyecto Norte ChuquisacaCORDECH, Sucre.

Desrosiers, Sophie.

1982 Métier à tisser et vêtement andins, ou, le tissu comme être vivant. Centre Culturel Latino-Américain (CETECLAM), Paris.

1997 Lógicas textiles y lógicas culturales en los Andes. In Saberes y Memorias en los Andes, editado por Th. Bouysse-Cassagne, pp. 325-349. Institut des hautes études de l'Amérique Latine (IHEAL) - Université Paris III / Institut français d'études andines (IFEA), Paris/Lima.

Douglas, Mary.

1986 How institutions think. Syracuse University Press, Syracuse, NY. 
Dransart, Penelope.

2002 Coloured knowledges: vision and the dissemination of knowledge in Isluga, northern Chile. In Knowledge and learning in the Andes, editado por Henry Stobart \& Rosaleen Howard, pp 56-78. Liverpool University Press, Liverpool.

2016 The sounds and tastes of colours: hue and saturation in Isluga textiles. Nuevo Mundo Mundos Nuevos. Dispinible en: https://journals.openedition.org/ nuevomundo/69188

2018 Mind's Eye and Embodied Weaving: Simultaneous Contrasts of Hue in Isluga Textiles, Northern Chile. Textile Society of America Symposium Proceedings 2018. Disponible en: https://digitalcommons.unl. edu/tsaconf/1126/

Espejo, Elvira.

2010 Una experiencia en la práctica textil. Una visión desde adentro. In Ciencia de las mujeres, editado por Denise Arnold \& Elvira Espejo. Instituto de Lengua y Cultura Aymara, La Paz.

Femenias, Blenda B.

1987 Color and Design in Andean Warp-Faced Fabrics. The Weaver's Journal 12(1): 44-46.

Fernández López, Arabel.

2008 Simbolismo multicolor. La artesanía textil de San Ignacio de Loyola. Gaceta Cultural del Perú 35: 12-13.

Floch, Jean-Marie \& Félix Thürlemann.

1986 Semi-symbolique. In Sémiotique: Dictionaire raisonné de la théorie du langage Vol. 2, editado por Algirdas J. Greimas y Joseph Courtés, pp. 203-206. Hachette, Paris.

Greimas, Algirdas Julien.

1984 Sémiotique figurative et sémiotique plastique. Actes Sémiotiques- Documents Vol. 6o. Group de Recherches Sémio-linguistiques (GRSL)- EHESS, Paris.

Havenon, Georgia de.

2004 Appropriating Color: Discontinuous Warp and Weft Textiles. In Tejiendo sueños en el Cono Sur. Textiles andinos: Pasado, presente y futuro, editado por Victòria Solanilla Demestre, pp. 83-88. Grup d'Estudis Precolombins- Departament d'ArtUniversitat Autònoma de Barcelona, Barcelona.

Lévi-Strauss, Claude.

1962 La pensée sauvage. Plon, Paris.

1964 Le cru et le cuit (Mythologiques 1). Plon, Paris.

1968 L'Origine des manières de table (Mythologiques 3). Plon, Paris.
Meisch, Lynn Ann.

1985a. Symbolism in Tarabuco, Bolivia, Textiles. In Weaving and Symbolism in the Andes. Andean Studies Occasional Papers Vol. 2, editado por Jeanette E. Sherbondy, pp. 1-25. Center for Latin American and Caribean Studies Indiana University, Bloomington.

1985b Fullus. Ikat blankets of Tarabuco, Bolivia. The Weavers Journal X(1): 54-58.

1986 Weaving Styles in Tarabuco, Bolivia. In The Junius B. Bird Conference on Andean Textiles, editado por Ann Pollard Rowe, pp. 243-26o. The Textile Museum, Washington.

1987 The living Textiles of Tarabuco, Bolivia. In Andean Aesthetics: Textiles of Peru and Bolivia, editado por Blenda Femenias, pp. 46-58. Elvejhem MuseumUniversity of Wisconsin, Madison.

Phipps, Elena J.

2003 Color in the Andes: Inka Garments and 17th-Century Colonial Documents. Dyes in History and Archaeology 19: 51-59.

Platt, Tristan.

1978 Symétries en mirroir. Le concept de yanantin chez les Macha de Bolivie. Annales ESC 33(5-6): 1081-1107.

Rouma, Georges.

1933 Quitchouas et Aymaras. Étude des Populations Autochones des Andes Boliviennes. Société Royale Belge d'Anthropologie et de Préhistoire, Bruselas.

Seibold, Katharine E.

1992 Textiles and Cosmology in Choquecancha, Cuzco, Peru. In Andean Cosmologies through Time. Persistence and Emergence, editado por Robert Dover, Katharine Seibold \& John McDowell, pp. 166-201. Indiana University Press, Bloomington.

Walle, Paul.

1914 Bolivia. Its People and Its Resources, Its Railways, Mines, and Rubber-Forests. Traducción de Bernard Miall. T. Fisher Unwin, Londres.

Zorn, Elayne.

1987 Un análisis de los tejidos en los atados rituales de los pastores. Revista Andina 5(1): 489-526. 